\title{
Acervos Escolares e a Pesquisa em História da Educação Matemática
}

\author{
Diogo Franco Rios' \\ Laura Leal Moreira"
}

'Universidade Federal de Pelotas (UFPel), Pelotas/RS - Brasil

"Universidade Federal do Paraná (UFPR), Curitiba/PR - Brasil

RESUMO - Acervos Escolares e a Pesquisa em História da Educação Matemática. Apresentamos reflexões a respeito do tratamento, preservação, organização e disponibilização de documentos escolares realizadas no âmbito do Projeto Estudar para Ensinar: práticas e saberes matemáticos nas escolas normais do Rio Grande do Sul (1889-1970), mais particularmente a partir de experiências de trabalho no Instituto Estadual de Educação Assis Brasil, de Pelotas. Para tal, traremos diálogos e aproximações com campos científico-profissionais que lidam com a preservação dos acervos e que foram imprescindíveis para o trabalho que realizamos e que apontam para a importância de um diálogo interdisciplinar entre esses campos quando da realização de pesquisas em História da Educação Matemática junto a esses acervos.

Palavras-chave: Acervos Escolares. Memória Institucional. Preservação Documental. História da Educação Matemática.

ABSTRACT - School Collections and the Research in History of Mathematical Education. We present reflections on the treatment, preservation, organization, and availability of school documents carried out within the scope of the Project Study to Teach: mathematical practices and knowledge in normal schools in Rio Grande do Sul (1889-1970), more particularly from work experiences at the Instituto Estadual de Educação Assis Brasil in Pelotas. To this end, we will bring dialogues and approximations with scientificprofessional fields that deal with the preservation of the collections, which were essential for the work that we do and that point to the importance of an interdisciplinary dialogue between these fields when conducting research in the History of Mathematical Education with these collections. Keywords: School Collections. Institutional Memory. Document Preservation. History of Mathematical Education.

Educação \& Realidade, Porto Alegre, v. 46, n. 2, e112059, 2021 
Acervos Escolares e a Pesquisa em História da Educação Matemática

\section{Introdução}

O presente artigo tem como objetivo apresentar algumas provocações a respeito dos compromissos que podem ser assumidos por nós, historiadores da educação matemática, frente aos arquivos institucionais aos quais nos vinculamos durante nossas práticas de pesquisa. Tais provocações se constroem a partir de uma revisão de literatura do campo da História da Educação, na qual identificamos aproximações com a Arquivologia e a Museologia, e que serão usadas para essa problematização que pretendemos trazer aqui.

O debate a respeito da vinculação dos historiadores da educação aos arquivos escolares e sua preocupação com as condições desses espaços de guarda dos vestígios das práticas educativas escolares já produziu dossiês específicos em revistas científicas da área, como aqueles publicados pela Revista Brasileira de História da Educação e pela Revista Pro-Posições, ambas em 2005, demonstrando uma crescente preocupação com

[...] a preservação de acervos e a atenção aos primados da arquivística e da museologia, enredando os historiadores da educação na discussão sobre a cultura material, o exercício do arquivamento e do descarte e as técnicas específicas de conservação de cada suporte ou objeto. Tais interlocuções têm ampliado ainda mais o horizonte do trabalho em história da educação, ao mesmo tempo provocando fissuras no que se considera a seara do historiador e questionando fronteiras disciplinares (Vidal, 2005a, p. 71-72).

Uma das inspirações para trazer a questão para o debate, especificamente para historiadores da educação matemática, surgiu em função de uma tensão produzida por uma instituição escolar na qual uma pesquisadora de nosso grupo pretendia investigar seu acervo existente, ainda não organizado sistematicamente. A coordenação do museu escolar reivindicou que, no período em que a pesquisa estivesse acontecendo, colaborássemos, de algum modo, com a organização do arquivo como um todo, que se encontra em processo de transição de arquivo morto para arquivo histórico, quando os documentos do passado institucional se integrarão, de certo modo, ao arquivo corrente, constituindo-se em um novo conjunto, o arquivo permanente (Vidal, 2005b).

Trata-se de uma instituição escolar municipal junto à qual, já há alguns anos, temos defendido a relevância de cuidar do acervo documental, dada a importância da instituição para a cidade de Pelotas-RS. É necessário dizer que não se tratou de uma negociação simples ou de um toma-lá-dá-cá, mas de uma provocação honesta, um sincero pedido de ajuda de uma instituição escolar. Como tantas outras, essa escola se vê premida para ignorar sua memória institucional, ignorando um volume considerável de resíduos e indícios das práticas educativas que, a rigor, já não precisariam estar sendo guardados, uma vez que representam certo incomodo para a instituição. 
Os argumentos, ali e em outros lugares, indicam as demandas por espaço e as dificuldades em conseguir, com a prefeitura, a concessão de horas para um responsável institucional e o conjunto de condições necessárias para conservá-los e acondicioná-los adequadamente.

Outra inspiração surgiu a partir de debates realizados entre os participantes do Projeto de Pesquisa interinstitucional Estudar para Ensinar: práticas e saberes matemáticos nas escolas normais do Rio Grande do Sul (1889-1970)ํำ (Búrigo et al., 2016), que, além dos compromissos assumidos com o CNPq, ocupou-se do cuidado com o acervo ligado ao ensino de matemática presente no arquivo escolar do Instituto Estadual de Educação Assis Brasil (IEEAB), em Pelotas e da guarda e cuidado com o acervo do Laboratório de Matemática do Instituto Estadual de Educação General Flores da Cunha, em Porto Alegre, em função de uma grande reforma pela qual passa a Instituição. No âmbito desse Projeto de Pesquisa, foi reconhecida a importância de buscar aproximações com os campos científicos ligados à conservação, gestão e disponibilização de acervos documentais, para capacitar a equipe, tanto professores quanto alunos, para inventariar as fontes dos arquivos das instituições participantes e para produzir, junto ao Centro de Documentação e Acervo Digital da Pesquisa da Universidade Federal do Rio Grande do Sul (CEDAP- UFRGS) um acervo digital a respeito das práticas de formação para o ensino dos saberes matemáticos no âmbito das instituições formadoras de professores primários participantes (Rios; Rodrigues, 2020).

Durante o $1^{\circ}$ Seminário Práticas e Saberes Matemáticos nas Escolas Normais do Rio Grande do Sul, realizado nos dias 24 e 25 de maio de 2018, na UFRGS, ocorreram atividades específicas para se debater aproximações com a Museologia e a Ciência da Informação, quando se debateu, entre outras questões, aspectos relativos à curadoria digital.

Trata-se de uma questão diferente daquela que já foi considerada a respeito do papel que os arquivos escolares, enquanto lugares de memória, podem oferecer para a formação de professores de Matemática (Rios, 2015a). Não retomaremos, aqui, essa questão, ainda que consideremos relevante reafirmar alguns aspectos a respeito da relação entre os arquivos escolares e a historiografia da educação matemática.

A seguir, no decorrer do texto, faremos algumas provocações sobre os limites e possibilidades da atuação de historiadores da educação matemática na preservação e conservação dos arquivos escolares e seus acervos, e como as posições tomadas podem repercutir para o fortalecimento ou o enfraquecimento das relações entre os pesquisadores e as instituições que os acolhem para a prática de pesquisa.

\section{Apresentando a Questão}

Há algum tempo, a História da Educação Matemática tem se mostrado sensível à importância dos documentos escolares para a produção do conhecimento, tanto que diversos pesquisadores e grupos de pesquisa têm empreendido um esforço considerável para viabilizar o 
Acervos Escolares e a Pesquisa em História da Educação Matemática

acesso às instituições escolares e aos seus acervos, de modo a localizar vestígios das práticas relativas aos processos de aprender e ensinar Matemática, nos diversos períodos da matemática escolar brasileira.

Esses materiais, que podem ser encontrados ainda preservados nas instituições escolares (a saber, documentos referentes às mais diferentes atividades - administrativas ou pedagógicas - e objetos e imagens antigas da escola) têm sua importância já bastante reconhecida na produção da História da Educação e, consequentemente, possuem potencial para a historiografia da educação matemática, uma vez que

[...] permitem não apenas a percepção dos conteúdos ensinados, a partir de uma análise dos enunciados e das respostas; mas o entendimento do conjunto de fazeres ativados no interior da escola. Assume destaque, por exemplo, a maneira como o espaço gráfico da página de exercício, do caderno ou da prova é organizado; utilizando-se de fórmulas indicativas de início ou encerramento de atividades ou dia letivo; definindo uma hierarquia de saberes... [...] esses objetos culturais e muitos outros, individuais e coletivos, necessários ao funcionamento da aula trazem as marcas da modelação das práticas escolares, quando observados na sua regularidade. Mas portam índices das subversões cotidianas a esse arsenal modelar, quando percebidos em sua diferença, possibilitando localizar vestígios de como os usuários lidam inventivamente com a profusão material da escola e das mudanças, às vezes imperceptíveis, que impetram nessas mesmas práticas escolares (Vidal, 2005b, p. 16-17).

A busca por tais fontes se justifica pela ampliação dos campos de interesse e das questões investigativas que têm sido colocadas para a História da Educação, em sua aproximação com a História Cultural, como explica Maria João Mogarro:

A atenção que os historiadores da educação crescentemente vêm atribuindo aos arquivos escolares radica numa atitude de diálogo plural, em que a questão das fontes de informação emerge como uma prioridade no quadro teórico-metodológico da história da educação e da história cultural. Torna-se urgente localizar, sistematizar, organizar e divulgar essas fontes, problematizando-as e validando-as, de forma que elas possam alimentar os novos temas e objectos de estudo incluídos no campo científico da história da educação: os alunos, nas suas especificidades (como a atenção renovada que tem sido dada à infância), os professores e a profissão docente, a formação de professores, as instituições escolares, a educação não formal, as questões de género, os públicos escolares minoritários, os quotidianos escolares, os saberes pedagógicos, a circulação e a apropriação de modelos culturais e as formas que os veiculam (Mogarro, 2005a, p. 88).

É preciso considerar, inclusive, que a busca por documentos escolares não se restringe às instituições educativas, mas inclui acervos 
institucionais ligados a centros de documentação de grupos de pesquisa, os quais têm assumido o cuidado e a guarda de acervos de várias escolas que não têm condições de tratar, preservar e conservar boa parte dos documentos relativos ao passado da instituição ou, o que não é exceção, não reconhecem a importância da preservação de sua memória institucional. Tais centros empreendem um esforço importante para tentar reduzir os danos causados pela inexistência, no país, de uma política de preservação para os documentos escolares que oriente a gestão dos acervos, permitindo que "[...] a avaliação documental fique sob a responsabilidade da própria escola, que, descartando seus documentos sem critérios técnicos ou científicos, está sujeita a equívocos por vezes irreversíveis" (Barletta, 2005, p. 112).

Mesmo fora das instituições escolares ou dos centros de documentação, há um importante número de pesquisadores em busca de vestígios pessoais das práticas educativas ligadas à Matemática e à memória de seus personagens, contemplando inclusive uma importante produção de fontes orais que carrega, como lhe é próprio, o potencial de responder questões que muitas vezes não podem ser explicadas a partir dos vestígios materiais.

O compromisso de tais pesquisadores vai na direção de superar o limite dos vestígios circunscritos ao suporte material. Antonio Viñao reconhece que os cadernos (e nós, aqui, nos permitimos extrapolar para todos os outros vestígios das práticas escolares) não comportam indícios do universo das práticas orais, que não se configuram ao suporte escrito, mas que, todos sabemos, compõem os cotidianos escolares.

Nem tudo está nos cadernos. Eles silenciam, não dizem nada sobre as intervenções orais ou gestuais do professor e dos alunos, sobre seu peso e o modo como ocorrem e se manifestam, sobre o ambiente ou clima da sala de aula, sobre as atividades que não deixam pistas escritas ou de outro tipo, como os exercícios de leitura (a leitura oral, por exemplo) e todo o mundo do oral (Viñao, 2008, p. 25).

Retomando a questão dos vestígios materiais, dada a aparente unanimidade quanto à importância dos documentos escolares para a produção científica da área, a questão que se coloca aqui diz respeito ao que podemos ou devemos fazer quando o conjunto de documentos escolares que nos interessam requerem, às vezes urgentemente, ações para viabilizar sua preservação, recuperação, organização e conservação.

Há algum tempo frequentando depósitos de documentos escolares, espaços onde, assim como nós, diversos pesquisadores têm concentrado seu locus de pesquisa, nos deparamos com realidades semelhantes àquelas já apontadas por colegas da História da Educação: as condições dos acervos escolares são, em sua maioria, bastante precárias, indicando a falta de uma sensibilidade documentária (Regazzini, 2001) e expondo o conjunto de objetos e documentos lá existentes a uma condição de iminente desaparecimento. 
Acervos Escolares e a Pesquisa em História da Educação Matemática

Amontoados em porões, debaixo de escadas, em salas apertadas, distribuídos ao acaso em armários e caixas, descuidados e sem interesse, documentos, quase sempre administrativos, além de coleções de instrumentos científicos, livros didáticos, móveis antigos, troféus, medalhas, entre outros objetos, sobrevivem a intempéries, goteiras, condições de insalubridade, falta de identificação, organização e armazenamento adequado na maioria das escolas (Souza, 2013, p. 205).

Problematizar as condições precárias em que tais materiais se encontram e a consequente necessidade de revisão dos limites de nossa atuação junto aos acervos escolares, considerando a possibilidade de colaborarmos com, pelo menos, a redução da velocidade com que têm desaparecido, parece-nos uma questão pertinente para ser discutida com os pesquisadores da História da Educação Matemática.

A proposição de nos ocuparmos da discussão sobre os limites da atuação do pesquisador interessado por acervos escolares se alia ao debate que, há mais de uma década, tem sido ponto de pauta entre alguns historiadores da educação, como já mencionado. No âmbito desse debate, Maria João Mogarro considera que

[...] a tarefa de recuperar, preservar, estudar e divulgar o património educativo, nomeadamente os arquivos escolares, adquire um novo sentido e urgência, que passa pela necessidade de definir orientações e dar consistência ao movimento que hoje se faz sentir, tanto em nível social como científico, sobre a escola, a sua história e memória (Mogarro, 2005b, p. 114)

Apesar do reconhecimento da relevância desses espaços e de seu potencial, ações concretas de colaborar com eles não têm se constituído compromisso para a maioria dos pesquisadores.

Embora já venha ocorrendo uma discussão em torno das questões que norteiam a preservação do patrimônio documental, ainda assim existem poucas as iniciativas concretas. Por essa razão, torna-se importante realizar estudos acerca de arquivos, bibliotecas, museus, centros de documentação, pois esses locais reúnem documentos de origem diversa (Furtado, 2011, p. 151).

Um reduzido número de trabalhos de pesquisa do campo da História da Educação tem conciliado a análise das fontes com a preservação documental, como, por exemplo, Moraes, Zaia e Vendrameto (2005), Menezes (2011) e Batista e Schmidt (2018). Em geral, tais iniciativas se estabelecem em função do reconhecimento das condições precárias dos acervos e do risco iminente de desaparecerem. No entanto, mesmo por esses pesquisadores, se reconhece que tal postura não é frequente, apesar da demanda ser bastante comum nos acervos em que pesquisam:

Tal percurso apresentou-se como um diferencial, uma vez que o mais comum tem sido os investigadores, ao realiza- 
Rios; Moreira

rem suas pesquisas nas instituições, utilizarem os acervos como fonte, dar a estes uma ordem precária, apenas o suficiente para o desenvolvimento da pesquisa em curso, e os abandonarem após a finalização delas. Essas investidas deliberadas e sem um plano de organização dos acervos não poucas vezes resultam em perdas ou alterações nos suportes por falta de manuseio correto e outros cuidados. Os trabalhos de conservação, descrição, acondicionamento ficam para outros. Essas práticas deixam marcas nos acervos, com lacunas e ordenações precárias, fora da ordem original. São recordações, com períodos ou temas específicos, em geral sobre os quais se detiveram os pesquisadores em suas investigações (Menezes, 2011, p. 99-100).

A provocação que trazemos aqui não tem a pretensão de indicar um final fatídico, caso não nos integremos à tarefa de colaborar com a preservação e sistematização dos acervos escolares durante nossas práticas de pesquisa, até porque, como diria Julia (2001, p. 17), “[...] o historiador sabe fazer flechas com qualquer madeira”. A questão é um tanto outra: será que compete a nós assumirmos mais essa responsabilidade e a incluirmos entre nossas práticas de pesquisa? Que posição seria a mais apropriada para nós, enquanto praticantes de pesquisa que reconhecem a importância desses vestígios? O quanto podemos e devemos fazer junto aos arquivos escolares? Seria possível a área assumir um ethos que articulasse a produção historiográfica à preservação, organização e conservação documental, no âmbito das instituições escolares? Tais compromissos podem ser associados a uma prática disciplinar ou trata-se de uma questão de foro privado do pesquisador?

Por um lado, é importante reconhecer que a preservação documental não tem sido a finalidade ou um compromisso prioritário da História da Educação Matemática. Por entender-se que essa finalidade ou compromisso, diferentemente, têm sido atribuídos à Arquivologia e/ou à Museologia, poderia parecer excessivo defender que tal função devesse ser assumida por nós como parte de um ethos profissional. Por outro lado, considerando que somos diretamente interessados nos materiais contidos nos arquivos escolares - mortos, correntes ou históricos -, que não há uma política pública que reconheça sua relevância, e que parte deles se encontram em vias de desaparecer, não parece razoável que assumíssemos uma parcela do cuidado e o compromisso em construir parcerias para valorizá-los e conservá-los?

No que tange ao campo de História da Educação, Batista e Schmidt (2018), ao apresentarem o percurso trilhado para acessar os acervos e as fontes documentais sobre as primeiras iniciativas de atendimento educacional à primeira infância no estado de Santa Catarina, refletem e discutem acerca da dificuldade no acesso e da necessidade da conservação dos acervos dessa natureza para a escrita da história da Educação Infantil, nesse caso, no estado de Santa Catarina. Todavia, apesar desse panorama exposto pelas autoras, ainda são poucos os trabalhos que trazem à tona esta questão e, após uma vasta pesquisa, não foram 
Acervos Escolares e a Pesquisa em História da Educação Matemática

encontrados outros registros desse movimento, no campo da História da Educação.

O que defendemos é que a História da Educação Matemática poderia encontrar modos de se solidarizar e se comprometer com os espaços de preservação escolar e, se possível, criar outros sentidos para sua existência. Tememos, não apenas por mero pessimismo, que esses espaços possam deixar de existir, em boa parte das escolas, se os sistemas digitais absorverem os dados das trajetórias acadêmicas dos alunos, limitando-se aos quadros correntes e descartando os documentos originais.

Ainda que o foco deste texto seja uma discussão em torno da preservação e conservação dos documentos escolares, não pretendemos diminuir a demanda colocada ao historiador para compreender, problematizar, interpretar e explicar essas fontes históricas, uma vez que oferecem indícios do passado e carecem de um aprofundado exercício reflexivo. Diante disso, talvez caiba retomar a pergunta: em que esse debate nos toca? Não seria apropriado deixar a cargo dos pesquisadores do campo da Arquivologia e Museologia a responsabilidade pela tarefa de lidar com a preservação dos acervos, nos restringindo à produção historiográfica ligada à Matemática?

Acervos escolares ligados à Educação Básica, em geral, estão longe de poder ser objetos de atenção exclusiva da Museologia, da Arquivologia ou da Ciência da Informação, dada a inexistência, exceto em casos muito particulares, de colocações para esses profissionais nas escolas brasileiras. Desse modo, não nos parece razoável esperar que a preservação dos acervos escolares seja assumida por esses profissionais sem que haja articulação com pesquisadores da área da História da Educação e, no nosso caso, pesquisadores da História da Educação Matemática.

Além do ganho para a memória institucional das escolas a que nos vinculamos, uma aproximação com os conhecimentos arquivológico e museológico pode nos provocar na direção de pensarmos de que modo os vestígios das práticas de ensinar e aprender Matemática precisam ser preservados, problematizando o exercício da conservação e do descarte, além de possibilitar reflexões a respeito do que e para que conservar.

Se entendermos pertinente comprometermos parte de nossas horas de pesquisa com o fortalecimento e consolidação desses espaços, julgamos que temos a chance de melhor localizar outras fontes de pesquisa e constituirmos outras parcerias, como com associações de exalunos, por exemplo, que, quando existem, muitas vezes se interessam e investem algo das suas atividades na preservação da memória da instituição a que estiveram ligados e à sua trajetória escolar.

Além disso, esforços em colaborar com a consolidação de arquivos institucionais, no intuito de torná-los arquivos históricos, podem melhorar o trânsito institucional em função do fortalecimento dos laços entre a universidade e a escola, que poderá vir a reconhecer que não se trata de uma relação extrativista ou predadora, mas de colaboração 
e apoio mútuo, em defesa da memória institucional (Rios; Rodrigues, 2020).

Participar do debate sobre como lidar com esses materiais institucionais, e de a quem compete essa tarefa, passa, necessariamente, pela gestão do acervo, que inclui ações de conservação e descarte. Nesse sentido é que a atuação da comunidade de pesquisadores em História da Educação pode ocupar uma função de interesse para a área, permitindo-nos elencar questões, como: que tipo de organização de arquivo escolar pode ser útil e interessante para nossa prática de pesquisa? Que conjuntos de documentos escolares podem ser considerados caros para História da Educação Matemática? O que, dentre o conjunto de documentos existentes, nos interessa? Como podemos participar da gestão desses acervos e da produção de inventários? Em que condiçõos mínimas de preservação, organização e acondicionamento esses conjuntos podem estar acessíveis para a produção historiográfica, nosso foco principal?

A comunidade escolar, além de potencial interessada na organização dos arquivos, também deve participar das decisões, já que um arquivo escolar não supõe a guarda irrestrita dos vestígios do passado institucional, mas como explica Vidal (2005b), a organização e o descarte dos vestígios escolares fazem parte do mesmo processo que, ao se realizar, atribui novos sentidos ao que se decide preservar, já que sua conservação se estabelece por procedimentos técnicos e reconhecimento de sua importância para o presente e o futuro.

Contudo, a tarefa de participar, de colaborar com os arquivos escolares não se encerra quando da definição do que preservar e aquilo que se vai descartar, uma vez que “[...] este trabalho ficará incompleto se não se colaborar no tratamento mais geral desses materiais, que permita dar-lhes visibilidade, participando na melhoria da qualidade cultural da cidade" (Felgueiras, 2005, p. 99).

Apesar de se constituir em uma tarefa exigente, a reivindicação de Margarida Louro Felgueiras parece de grande lucidez e se constitui, em nossa compreensão, ponto crucial de interesse para nosso campo de pesquisa: a partir da disponibilização das fontes teremos a possibilidade de seguir com o desenvolvimento de nossas pesquisas e com o aprofundamento das explicações historiográficas que produzimos. Nesse sentido, a Ciência da Informação também tem prestado uma colaboração significativa, possibilitando não apenas para comunidade em torno da escola, mas, de modo mais amplo, a conversão dos documentos escolares para versão digital.

Nesse sentido, vale dizer que, no que tange à disponibilização dos documentos escolares de diversas naturezas, os pesquisadores da História da Educação Matemática têm se empenhado, nos últimos anos, para a constituição de acervos digitais de livre acesso, visando à disponibilização do maior contingente possível de documentos digitais, incluindo as diversas tipologias dos documentos referentes ao ensinar e aprender Matemática, desde a legislação até os mais variados documen- 
Acervos Escolares e a Pesquisa em História da Educação Matemática

tos escolares. Entre as iniciativas existentes, destacamos o repositório do Grupo de Pesquisa de História da Educação Matemática (GHEMAT) que, alocado na Universidade Federal de Santa Catarina ${ }^{2}$, tem oferecido ao público um conjunto considerável de documentos escolares em sua versão digital para qualquer pessoa interessada na temática.

Nesse mesmo sentido, apresentamos neste texto as possibilidades e os limites que viemos trilhando, junto à parceria estabelecida no IE$\mathrm{EAB}$, na cidade de Pelotas, vinculado ao projeto de pesquisa já mencionado. Quais as ações que dois Educadores Matemáticos e seus orientandos vem tomando perante o cenário de seus lócus de pesquisa? Como a parceria entre uma escola e uma universidade extrapolou a relação habitual do palco para os estágios e avança na conscientização da comunidade escolar para a importância da manutenção e preservação de seus vestígios escolares? O que acreditamos que nos compete?

\section{Avançando na Discussão Refletindo Sobre uma Experiência no IEEAB}

Nesta seção do texto, traremos das experiências do campo da Educação Matemática: o que dois profissionais da área de História da Educação Matemática, podem trazer para esse debate? Como nossas práticas de pesquisa vem sendo guiadas? Que experiências de preservação, ligadas a iniciativas começadas há cinco anos, inclusive a partir do Programa Institucional de Bolsas de Iniciação à Docência (PIBID), podem e merecem ser destacadas pelos graduandos? Como essas experiências foram se consolidando?

Em meados de 2015, a partir da criação do Projeto de Pesquisa no âmbito da Universidade Federal de Pelotas (UFPel), Educação Matemática no Rio Grande do Sul: instituições, personagens e práticas (18901970) (Rios, 2015b) ${ }^{3}$, se estabeleceu uma relação de parceria junto com o IEEAB. Desde então, o projeto buscou assumir o compromisso de conservação e de constituição de uma coleção digital do acervo escolar, com o objetivo de disponibilizar esses materiais para pesquisadores e interessados na área, além da disponibilização da versão digital de seu acervo à própria escola (Rios; Rodrigues, 2020).

Atualmente, após a realização dos projetos de pesquisa mencionados, nos encontramos em fase final de organização dos documentos que contém vestígios de práticas de Matemática de sala de aula e disponibilização coleção digital do acervo escolar.

Desse longo período de aproximação, é importante ressaltar que a relação entre a universidade e a escola requereu paciência, compreensão e muito diálogo; o que um professor de Matemática busca e quer ao visitar os acervos da escola? Logo os acervos que ficam no espaço reservado aos documentos antigos e inativos para a instituição? O estranhamento já era de se esperar. A comunidade escolar, em suma, desconhecia a importância de seu acervo para as práticas de pesquisas do campo da História da Educação. 
A falta de melhor compreensão sobre a relevância desses arquivos nem de longe nos parece "culpa" da escola, mas efeito da falta de políticas públicas que defendam a relevância do valor desses vestígios como possibilidade para problematizar os processos educativos e para o fortalecimento dos elos da identidade escolar. A inexistência de profissionais do campo para tratar desses materiais indica, ainda, a pouca atenção atribuída aos vestígios das experiências educacionais dos personagens do interior da cultura escolar - gestores, educadores e alunos, que acabam por não terem suas memórias reconhecidas no bojo dos discursos educativos institucionais.

\begin{abstract}
Ao lado das iniciativas pertinentes ao presente, a escola pode ser um espaço em que os vestígios das antigas experiências educacionais tenham lugar de preservação e onde as práticas que ali já foram presenciadas, adequadas ou não, encontram oportunidade de circulação e diálogo. Isso interromperia a descontinuidade entre o passado e o presente, que parece imposta em sociedades como a nossa, nas quais se privilegia o novo em vez do antigo e o futuro ante o passado, viabilizando-se a reconstrução do elo com as experiências educativas vividas no passado institucional, cumprindo o que Nora (1993) chamou de 'dever de memória' (p. 17) (Rios; Rodrigues, 2020, p. 72).
\end{abstract}

Além disso, o mais usual era que a parceria estabelecida entre um curso de licenciatura e a instituição escolar fosse aquela direcionada ao cumprimento dos estágios supervisionados dos licenciandos ou em projetos de ensino como foi o caso do PIBID. Então, quando falamos em práticas de preservação e manutenção do acervo documental, houve certo estranhamento por não se tratar de uma proposta comum, ainda mais vinda de um professor do Curso de Licenciatura em Matemática.

A seguir, apresentaremos o que pudemos experimentar ao longo desse percurso, trazendo alguns dos desafios e os modos como lidamos com eles, fossem em função das condições práticas de execução da pesquisa, fossem em função de questões relativas ao esforço de atuarmos em atividades que não fizeram parte de nossa formação inicial e dos alunos participantes.

A parceria com a instituição se iniciou ainda em 2013, quando se criou um eixo temático no âmbito do PIBID/UFPel/Matemática relacionado com a História da Educação Matemática, no âmbito de duas importantes instituições escolares de Pelotas, o Colégio Municipal Pelotense e o IEEAB. Tinha-se como objetivo fortalecer o elo entre diferentes gerações de educadores que atuaram nas instituições e os licenciandos em Matemática, além de refletir sobre como o conhecimento de suas práticas poderia contribuir com a formação de novos educadores. $\mathrm{Na}$ ocasião, ficou claro que seria uma oportunidade para os alunos participantes de "[...] se confrontarem com traços de uma cultura escolar, que vão desde a estrutura física até os vestígios relacionados com práticas de apropriação de propostas pedagógicas" (Souza; Rios; Silva, 2018, p. 143) e, assim, refletirem sobre seu próprio processo formativo. 
Acervos Escolares e a Pesquisa em História da Educação Matemática

Nesse primeiro movimento de aproximação, possibilitou-se que grande parte dos licenciandos em Matemática e bolsistas do PIBID tivessem seus primeiros contatos com a discussão sobre a importância da preservação e da manutenção dos acervos para a cultura escolar.

A partir de 2016, com o encerramento do referido eixo criado no PIBID da instituição e com as ações do Projeto de Pesquisa local já mencionado (Rios, 2015b), fortalecemos ainda mais a relação com o IEEAB e tivemos acesso ao acervo que se encontrava em um setor restrito da biblioteca da Instituição que, após cumpridas as etapas de higienização, organização e digitalização foram reorganizados no espaço destinado à sua guarda, mantendo a lógica estabelecida pela instituição escolar.

Entretanto, não foi uma aproximação simples. Foram necessárias muitas conversas e um processo de confiança mútua estabelecida durante os anos de trabalho entre professores e alunos da universidade e os gestores do Instituto, e contamos com uma atuação flutuante de alunos da Licenciatura em Matemática já que a maioria tinha um vínculo como voluntário. Alguns, ao se integrarem, não se identificavam com a abordagem, e outros chegaram a se formar e seguiram interessados na temática, a ponto de integrarem projetos de pós-graduação na área, como é o caso de uma das autoras deste trabalho.

$\mathrm{O}$ resultado dessa parceria favoreceu a preservação do acervo a que tivemos acesso e, em decorrência disso, colaborou com a preservação de vestígios ligados à cultura escolar da instituição, além de ter possibilitado o desenvolvimento de algumas pesquisas de mestrado no campo da História da Educação Matemática, e, ainda, de um conjunto interessante de resultados de pesquisa, publicados e apresentados em eventos científicos. Das pesquisas desenvolvidas, podem ser apontadas a dissertação de mestrado de Silva (2019), que apresentou narrativas de normalistas sobre a Matemática no Curso Normal do Instituto de Educação Assis Brasil ${ }^{4}$ entre as décadas de 1950 e 1960; a dissertação de Heidt (2019) , que apresentou um panorama sobre Matemática Moderna no Instituto no período de 1964-1979; e, por último, uma dissertação ainda em andamento que analisa saberes profissionais para ensinar Matemática que compunham a formação dos normalistas nos anos 1960 na mesma instituição.

Especialmente entre 2017 e 2020, em função da constituição do Projeto de Pesquisa que contou com financiamento do $\mathrm{CNPq}$, foi possível avançar no tratamento do acervo escolar, quando passamos a contar com uma a sala de trabalho, o que nos possibilitou melhores condições de higienização, organização e digitalização do material, os vestígios relacionados com as práticas de ensino da disciplina de Matemática e de Didática da Matemática (Rios; Rodrigues, 2020).

Em 2020, em função da crise sanitária estabelecida pelo coronavírus, os trabalhos presenciais no acervo escolar foram interrompidos, visando à segurança dos participantes do Projeto e dos próprios funcionários do IEEAB. Dessa maneira, como já havíamos digitalizado boa parte dos materiais localizados, higienizados e organizados, decidimos 
focar nossas ações a reta final do trabalho no acervo: o processo de produção de fichas catalográficas e a submissão das versões digitais dos documentos localizados no repositório institucional do CEDAP, setor da UFRGS, instituição copropositora do Projeto.

Convém ressaltar que estávamos diante de uma tarefa nova para o grupo de trabalho: a elaboração das fichas catalográficas e a produção de metadados, bem como a organização e submissão para o repositório digital mencionado. Diante da parceria estabelecida junto ao CEDAP, tivemos a oportunidade de contar com a colaboração de profissionais das áreas de Biblioteconomia e da Ciência da Informação, que foram indispensáveis para nos orientar nessa produção, uma vez que envolvia uma série de procedimentos e cuidados próprios desses campos que ainda não havíamos nos deparado.

Essa elaboração demandou cuidado, trocas e um importante diálogo formativo, evidenciando, mais uma vez, a importância de estabelecermos parcerias e aproximações com profissionais especializados dessas áreas acadêmicas para nossa atuação como educadores interessados em colaborar com um acervo escolar.

Após o trabalho de elaboração das fichas catalográficas, cerca de 1.700 páginas de documentos digitalizadas, distribuídas em conjuntos e pastas de documentos, foram enviados ao repositório digital do CEDAP e/ou estão em fase de submissão. Entre esses documentos, encontram-se especialmente diários de classe do Curso Normal, contendo registros das disciplinas de Matemática, Desenho, Didática Especial da Matemática, Didática da Matemática, Didática do Desenho, entre outras; pastas nominais de professores, contendo cópias dos documentos de identificação destes professores, atestados, certidões, portarias e memorandos; relatórios de estágios realizados pelas alunas normalistas; uma pasta de documentos relativos ao Departamento de Estudos Especializados (DEE)5; um livro de atas dos anos de 1959 1967, contendo registros de reuniões relacionadas com o Jardim de Infância que funcionava vinculado à Escola Normal Assis Brasil, como a instituição se chamava na época.

Para além do trabalho técnico associado ao acervo, uma das questões que nos parece importante destacar aqui foi a necessidade, tanto para os alunos quanto para os professores envolvidos, de fazermos aproximações teóricas e metodológicas que não tradicionalmente compõem a formação de um professor de Matemática, relacionadas aos campos que têm a preservação documental como dever de ofício, como já mencionamos. Foram muitas horas de estudo coletivo para superar

[...] os limites técnicos dos propositores do Projeto, por não possuírem formação específica relacionada com os campos de pesquisa que têm a preservação de patrimônio como dever de ofício, tivemos como um dos pontos de partida a busca por aproximações com a Museologia, a Arquivologia, a Biblioteconomia e a Ciência da Informação para dar suporte às ações da equipe e, assim, viabilizar e qualificar os processos de produção de inventário 
Acervos Escolares e a Pesquisa em História da Educação Matemática

das fontes dos arquivos das instituições participantes e a constituição do acervo digital pretendido (Rios; Rodrigues, 2020, p. 75)

Chegamos ao ponto final do projeto, que contou com financiamento do CNPq, em 2020, reconhecendo os avanços e colaboração efetivamente realizados, a importância do trabalho para preservação do acervo junto ao qual atuamos e considerando que os alunos participantes também conseguiram refletir sobre o quanto esse trabalho pode colaborar com a sua formação, a partir de problematização a respeito do ser professor de Matemática no presente e no passado, ao ter acesso a outras tantas experiências de professores que atuaram em diferentes momentos na instituição.

A experiência vivenciada desde o momento que iniciamos o PIBID, quando começamos uma vinculação dos licenciandos nos contextos escolares, não apenas ligada ao estágio, aqui nos referindo especificamente ao caso do IEEAB, além de integrá-los a um cotidiano escolar, em muito semelhante com os espaços onde estarão inseridos profissionalmente no futuro, essa convivência possibilitou que refletissem

[...] a respeito do papel dos professores de Matemática em diferentes momentos históricos vivenciados pela instituição, e como suas ações pedagógicas estiveram aderidas a certos modelos e discursos pedagógicos, e se expressaram em suas práticas cotidianas. Ao terem acesso a ações pedagógicas de outros professores, deslocados temporalmente e mediados pelos documentos poderão refletir sobre os modos sobre os modos como as prescrições educacionais existentes foram interpretadas e institucionalizadas, contribuindo para a discussão a respeito das tensões educacionais existentes entre as prescrições estabelecidas e o que delas se faz no interior das escolas (Rios, 2015a, p. 18).

Ou seja, para além da importância que a atuação no projeto teve para preservação daquele acervo escolar, possibilitou aos alunos participantes vivências relativas a aspectos do cotidiano da escola, com os quais os graduandos tinham pouco ou nenhum contato, como fica explícito na narrativa a seguir ${ }^{6}$, em que um deles conta sobre sua atuação no projeto ${ }^{7}$.

Estou vinculado ao IEEAB desde 2019 através de nosso projeto. Se eu pudesse falar só das coisas que eu aprendi dentro do Instituto, [eu falaria] da parte do trabalho do projeto mesmo, da parte técnica de manutencão e documentos oficiais, que era uma coisa que eu nunca tinha trabalhado, estar dentro do IEEAB fazendo esse projeto, esse trabalho no caso, me ajudou muito em relação ao [aprendizado] disso. Eu tenho que citar também a relação, mas não o tipo de relação 'padrão' dentro da escola, onde tu [professor] tá relacionado aos alunos, mas a relação do professor com os servidores... principalmente [porque no projeto] a gente tem muito contato com o pessoal da portaria ou o pessoal da secretaria. Então, acabou também que essas áreas dentro de uma escola, das quais eu não tinha muita noção ou noção nenhuma, eu acabei conhecendo muito, co- 
nhecendo as pessoas que estão ali, e foi uma experiência muito boa, foi um aprendizado muito importante para mim, e eu acho que principalmente porque dentro da faculdade a gente não tem tanta noção de que ali são pessoas, a gente vê várias coisas nos falando como agir ou temos disciplinas que nos dizem como fazer cada coisinha e a gente esquece que são pessoas [que estão ali], que têm uma história, que têm o dia a dia delas e que estar ali também é um trabalho e é muito complicado para todo mundo. E isso é uma coisa que a gente não para refletir. Então estar dentro do instituto, ter essa relação com esses servidores que a gente não teria a mesma relação como professores, é muito gratificante, é um ensinamento muito 'próprio' do fazer do projeto (Pedro, 19 dez. 2020).

Nos compete estar sensibilizados e buscar diálogos possíveis, para além dos aspectos de nossa formação, para podermos transitar em campos de trabalho que não nos são familiares a princípio. A partir daí, apesar de seguirmos sem uma formação formal em Arquivologia, Museologia ou em Ciência da Informação, temos práticas de pesquisa e experiências de trabalho em acervos que nos permitem atuar de maneira adequada na preservação e manutenção de acervos escolares cuja importância é fundamental para que se possa conhecer as práticas didáticas realizadas em diferentes momentos educacionais nas instituições a que nos ligamos, como já dissemos.

Dessa maneira, é importante que retomemos o debate a respeito do compromisso em atuar junto a acervos e de como este trabalho técnico influencia na formação de novos pesquisadores. Jorge (18 dez. 2020), ao nos relatar sua experiência com as práticas de pesquisa junto ao acervo, ressalta positivamente como isso o afetou enquanto futuro professor e pesquisador.

A experiência que tive no Instituto Assis Brasil foi muito interessante no que diz respeito, não somente à minha formação como professor, visto que tivemos contato ali... estudamos, [com] vestígios da instituição disponíveis naquele espaço, né? onde muitos profissionais como eu e meus professores, professores da área, também passaram e trabalharam, mas também com uma excelente experiência para um aspirante a pesquisador como eu, em quem sobrava vontade e faltava experiência e vivência. Estar naquele lugar e ter acesso aos documentos é muito enriquecedor e te faz, de certa maneira, abrir os olhos para o como estamos inseridos em um local complexo. Querendo ou não, estar lá dentro, da instituição, de uma instituição como o Assis Brasil, cuja história é tão rica e vasta, e ter acesso aos vestígios dessa história, ali dentro, foi sem dúvida uma ótima experiência, não só profissional como acadêmica e pessoal também. Acho que para além dos documentos, das discussões e dúvidas que surgiram ao longo do trabalho, né? foram os momentos que eu mais aprendi e cresci como profissional (Jorge, 18 dez. 2020).

Sem a pretensão de esgotarmos o debate, intentamos trazer algumas problematizações sobre o papel que historiadores da educação matemática podem desempenhar frente aos acervos escolares com os quais trabalham em suas práticas de pesquisa e apresentamos o processo de nosso grupo de trabalho junto a uma instituição escolar em que foi possível estabelecer uma parceria bem-sucedida. 
Acervos Escolares e a Pesquisa em História da Educação Matemática

Por fim, também as aproximações possibilitadas pelos projetos aqui mencionados, interessados na preservação da documentação escolar, se mostraram enriquecedoras para a formação de pesquisadores em História da Educação Matemática e de professores, uma vez que a participação de alguns alunos, bolsistas ou voluntários, favoreceu ampliar suas leituras a respeito da cultura escolar e viabilizou que tivessem acesso ao cotidiano da instituição a que se vincularam, valorizando práticas didáticas não apenas dos professores em exercício, mas daqueles de outras gerações que atuaram na instituição.

Esperamos que tenhamos conseguido estimular outros colegas da área a se aproximarem do debate que, há alguns anos, vem sendo trazido por historiadores da educação e dizem respeito à constituição e às condições atuais dos arquivos escolares, bem como à repercussão de nossas atuações profissionais junto a esses espaços de preservação da memória institucional.

Recebido em 11 de março de 2021 Aprovado em 19 de maio de 2021

\section{Notas}

1 Projeto que contou com financiamento do CNPq.

2 Sob a coordenação do prof. Dr. David Antonio da Costa, o Repositório Digital abriga as digitalizações dos documentos mobilizados nos projetos em andamento do GHEMAT (Costa; Valente, 2015), possuindo com conjunto considerável de documentos digitais. Para visita ao Repositório: <https://repositorio. ufsc.br/handle/123456789/1769>.

3 Projeto que contou com financiamento da FAPERGS.

4 Ao longo dos anos o IEEAB passou por várias mudanças em sua nomenclatura. Foi denominado de Escola Complementar de Pelotas, quando de sua fundação, em 1929, em 1940 passou se chamar Escola Complementar Assis Brasil, em 1943 passou para Escola Normal Assis Brasil. Em 1962 ficou instituída como Instituto de Educação Assis Brasil e, a partir do ano de 1997, incluiu estadual no nome (Amaral; Amaral, 2007 apud Silva, 2019).

5 Para saber mais sobre as ações realizadas pelo Departamento de Estudos Especializados (DEE), ver Rodrigues e Rios (2020).

6 Os relatos apresentados atenderam a um convite para falarem da experiência no Projeto e seguiram cuidados éticos, tendo sido realizada a assinatura do Termo de Consentimento Livre e Esclarecido (TCLE) que autoriza a divulgação em trabalhos acadêmicos. O TCLE encontra-se em posse dos pesquisadores.

7 Ambos os relatos são de discentes que atuam como bolsistas do Projeto Educação Matemática no Rio Grande do Sul, instituições personagens e práticas, sendo respectivamente, Bolsista PBIP-AF/UFPel e Bolsista PROBIC/FAPERGS. 


\section{Referências}

BARLETTA, Jacy Machado. Arquivos ou Museus: qual o lugar dos acervos escolares?. Revista Brasileira de História da Educação, v. 5. n. 2, p. 101-122, jul./dez. 2005. Disponível em: <http://periodicos.uem.br/ojs/index.php/rbhe/article/ view/38648/20179>. Acesso em: 11 nov. 2019.

BATISTA, Rosa; SCHMIDT, Leonete Luzia. Constituição de um Acervo Documental Sobre a História da Educação Infantil em Santa Catarina na Primeira Metade do Século XX. Revista Linhas, Florianópolis, v. 19, n. 41, p. 292-324, set./ dez. 2018. Disponível em: <https://www.revistas.udesc.br/index.php/linhas/ article/view/1984723819412018292>. Acesso em: 10 ago. 2020.

BÚRIGO, Elisabete Zardo; DALCIN, Andreia; DYNNIKOV, Circe Mary Silva da Silva; RIOS, Diogo Franco; FISCHER, Maria Cecília Bueno; PEREIRA, Luiz Henrique. Estudar para Ensinar: práticas e saberes matemáticos nas escolas normais do Rio Grande do Sul (1889-1970). 2016. 41 f. Projeto de Pesquisa. CNPq. Universidade Federal do Rio Grande do Sul, Porto Alegre, 2016.

COSTA, David Antonio; VALENTE, Wagner Rodrigues. O Repositório de Conteúdo Digital nas Pesquisas de História da Educação Matemática. Revista Iberoamericana Patrimônio Histórico-Educativo, Campinas, v. 1, n. 1, p. 96-110, jul./ dez. 2015. Disponível em: <https://doi.org/10.20888/ridphe_r.vli1.9231>. Acesso em: 08 set. 2020.

FELGUEIRAS, Margarida Louro. Materialidade da Cultura Escolar. A importância da museologia na conservação/comunicação da herança educativa. Proposições, Campinas, v. 16, n. 1, p. 87-102, jan./abr. 2005. Disponível em:<https:// periodicos.sbu.unicamp.br/ojs/index.php/proposic/article/view/8643756>. Acesso em: 21 ago. 2020.

FURTADO, Alessandra Cristina. Os Arquivos Escolares e sua Documentação: possibilidades e limites para a pesquisa em História da Educação. InCID: Revista de Ciência da Informação e Documentação, v. 2, n. 2, p. 145-159, jul./dez. 2011. Disponível em: <https://doi.org/10.11606/issn.2178-2075.v2i2p145-159>. Acesso em: 13 nov. 2019.

HEIDT, Makele Veronica. Matemática Moderna no Instituto Estadual de Educação Assis Brasil (1964-1979). 2019. 197 f. Dissertação (Mestrado em Educação Matemática) - Programa de Pós-Graduação em Educação Matemática, Universidade Federal de Pelotas, Pelotas, 2019. Disponível em: <http://guaiaca.ufpel. edu.br/handle/prefix/4582>. Acesso em: 23 fev. 2021.

JULIA, Dominique. A Cultura Escolar como Objeto Histórico. Revista Brasileira de História da Educação, v. 1, n. 1, p. 9-43, jan./jun. 2001. Disponível em: <http://periodicos.uem.br/ojs/index.php/rbhe/article/view/38749>. Acesso em: 23 maio 2019.

MENEZES, Maria Cristina. Descrever os Documentos - construir o inventário - preservar a cultura material escolar. Revista Brasileira de História da Educação, v. 11, n. 1 (25), p. 93-116, jan./abr. 2011. Disponível em: <http://periodicos. uem.br/ojs/index.php/rbhe/article/view/38508>. Acesso em: 30 maio 2019.

MOGARRO, Maria João. Arquivos e Educação: a construção da memória educativa. Revista Brasileira de História da Educação, v. 5, n. 2 (10), p. 75-99, jul./dez. 2005a. Disponível em: <http://periodicos.uem.br/ojs/index.php/rbhe/article/ view/38647>. Acesso em: 23 maio 2019.

MOGARRO, Maria João. Os Arquivos Escolares nas Instituições Educativas Portuguesas. Preservar a informação, construir memória. Pro-posições, Cam- 
Acervos Escolares e a Pesquisa em História da Educação Matemática

pinas, v. 16, n. 1 (46), p. 103-116, jan./abr. 2005b. Disponível em: <https://periodicos.sbu.unicamp.br/ojs/index.php/proposic/article/view/8643757>. Acesso em: 4 mar. 2021.

MORAES, Carmen Sylvia Vidigal; ZAIA, Iornar Barbosa; VENDRAMETO, Maria Cristina. Arquivos Escolares e Pesquisa Histórica: fontes para o estudo da educação brasileira. Pro-Posições, Campinas, v. 16, n. 1 (46), p. 117-133, jan./ abr. 2005. Disponível em: <https://periodicos.sbu.unicamp.br/ojs/index.php/ proposic/article/view/8643758>. Acesso em: 05 ago. 2020.

RAGAZZINI, Dario. Para Quem e o Que Testemunham as Fontes da História da Educação? Educar em Revista, Curitiba, UFPR, v. 17, n. 18, p. 13-28, 2001. Disponível em: <https://revistas.ufpr.br/educar/article/view/32815>. Acesso em: 07 ago. 2020.

RIOS, Diogo Franco. Contribuições dos Lugares de Memória para a Formação de Professores de Matemática. Acta Scientiae, Canoas, RS, v. 17, n. 4, Edição Especial, p. 5-23, 2015a. Disponível em: <http://www.periodicos.ulbra.br/index. php/acta/article/view/1452>. Acesso em: 04 mar. 2021.

RIOS, Diogo Franco. Educação Matemática no Rio Grande do Sul: instituições, personagens e práticas (1890-1970). Projeto de Pesquisa. FAPERGS. Pelotas, 2015b, $12 \mathrm{f}$.

RIOS, Diogo Franco; RODRIGUES, Janine Moscarelli. Para Guardar o que quer que se Guarde: dos acervos escolares à construção de uma coleção digital. In: BÚRIGO, Elisabete Zardo; DALCIN, Andreia; DYNNIKOV, Circe Mary Silva da Silva; RIOS, Diogo Franco; FISCHER, Maria Cecília Bueno (Org.). Saberes Matemáticos nas Escolas Normais do Rio Grande do Sul (1889-1970). 1. ed. São Leopoldo: Oikos, 2020. P. 69-90. Disponível em: <https://www.lume.ufrgs.br/ bitstream/handle/10183/217111/001116239.pdf?sequence=1>. Acesso em: 04 mar. 2021.

RODRIGUES, Janine Moscarelli; RIOS, Diogo Franco. Saberes Matemáticos Para Ensinar 'Fatos Fundamentais das Operações de Números Inteiros'. In: SEMINÁRIO NACIONAL PRÁTICAS ESCOLARES E SABERES MATEMÁTICOS NAS ESCOLAS NORMAIS, 1., 19 a 30 out. 2020, Porto Alegre. Anais... Porto Alegre: Universidade Federal do Rio Grande do Sul (UFRGS), 2020. P. 358-370. Disponível em: <http://www.ufrgs.br/escolasnormais/seminario-1 nacional/ANAISSeminrioNacional.pdf >. Acesso em: 04 mar. 2021.

SILVA, Vinicius Kerscher. Narrativas de Normalistas Sobre a Matemática no Curso Normal do Instituto de Educação Assis Brasil (1955-1968). 2019. $154 \mathrm{f}$. Dissertação (Mestrado em Ensino de Ciências e Matemática) - Programa de Pós-Graduação em Ensino de Ciências e Matemática, Universidade Federal de Pelotas, Pelotas, 2019. Disponível em: <http://guaiaca.ufpel.edu.br/handle/prefix/4788>. Acesso em: 30 out. 2019.

SOUZA, Luzia Aparecida; RIOS, Diogo Franco; SILVA, Heloísa da. O que Pode a História da Educação Matemática em Espaços Não Disciplinares?. In: DASSIE, Bruno Alves; COSTA, David Antonio da (Org.). História da Educação Matemática e Formação de Professores. 1. ed. São Paulo: Livraria da Física, 2018. P. 121150.

SOUZA, Rosa Fátima de. Preservação do Patrimônio Histórico Escolar no Brasil: notas para um debate. Revista Linhas, Florianópolis, v. 14, n. 26, p. 199-221, jan./jun. 2013. Disponível em: <http://hdl.handle.net/11449/125216>. Acesso em: 05 ago. 2020. 
VIDAL, Diana Gonçalves. Arquivos Escolares: desafios à prática e à pesquisa em história da educação - Apresentação. Revista Brasileira de História da Educação, v. 5, n. 2 (10), p. 71-73, jul./dez. 2005a. Disponível em: <http://periodicos.uem.br/ojs/index.php/rbhe/article/view/38646/20177>. Acesso em: 05 ago. 2020.

VIDAL, Diana Gonçalves. Cultura e Práticas Escolares: uma reflexão sobre documentos e arquivos escolares. In: SOUZA, Rosa Fátima de; VALDEMARIN, Vera Teresa (Org.). A Cultura Escolar em debate: questões conceituais, metodológicas e desafios para a pesquisa. Campinas: Autores Associados, 2005b. P. 3-30.

VIÑAO, Antonio. Os Cadernos Escolares como Fonte Histórica: aspectos metodológicos e historiográficos. In: MIGNOT, Ana Chrystina Venancio (Org.). Cadernos à Vista: escola, memória e cultura escrita. Rio de Janeiro: EdUERJ, 2008. P. 15-33.

Diogo Franco Rios possui doutorado em Ensino, Filosofia e História das Ciências pela Universidade Federal da Bahia (2012). Atualmente é professor do Departamento de Educação Matemática, da Universidade Federal de Pelotas, atuando no Curso de Licenciatura em Matemática e no Programa de Pós-Graduação em Educação Matemática. Líder do Grupo de Pesquisa em História, Currículo, Cultura e Educação Matemática.

ORCID: https://orcid.org/0000-0001-8391-5721

E-mail: riosdf@hotmail.com

Laura Leal Moreira possui mestrado pelo Programa de Pós-Graduação em Educação em Ciências e em Matemática da Universidade Federal do Paraná (UFPR) e, atualmente é doutoranda pelo mesmo programa. Membra do Grupo de Pesquisa Educação Matemática (UFPR) e, do Grupo de Pesquisa História Oral e Educação Matemática (GHOEM).

ORCID: https://orcid.org/0000-0001-7914-9526

E-mail: lauraamoreira@gmail.com

Editor-responsável: Luís Armando Gandin

Este é um artigo de acesso aberto distribuído sob os termos de uma Licença Creative Commons Atribuição 4.0 Internacional. Disponível em: <http:// creativecommons.org/licenses/by/4.0>. 